\title{
Mechanism of escape from nonsense-mediated mRNA decay of human $\beta$-globin transcripts with nonsense mutations in the first exon
}

\author{
GABRIELE NEU-YILIK, ${ }^{1,2}$ BEATE AMTHOR, ${ }^{1,2}$ NIELS H. GEHRING, ${ }^{1,2,4}$ SHARIF BAHRI, ${ }^{1,5}$ HELENA PAIDASSI, ${ }^{1,6}$ \\ MATTHIAS W. HENTZE, ${ }^{2,3}$ and ANDREAS E. KULOZIK ${ }^{1,2}$ \\ ${ }^{1}$ Department of Pediatric Oncology, Hematology and Immunology, University of Heidelberg, 69120 Heidelberg, Germany \\ ${ }^{2}$ Molecular Medicine Partnership Unit, University of Heidelberg and European Molecular Biology Laboratory, 69120 Heidelberg, Germany \\ ${ }^{3}$ European Molecular Biology Laboratory, 69117 Heidelberg, Germany
}

\begin{abstract}
The degradation of nonsense-mutated $\beta$-globin mRNA by nonsense-mediated mRNA decay (NMD) limits the synthesis of C-terminally truncated dominant negative $\beta$-globin chains and thus protects the majority of heterozygotes from symptomatic $\beta$-thalassemia. $\beta$-globin mRNAs with nonsense mutations in the first exon are known to bypass NMD, although current mechanistic models predict that such mutations should activate NMD. A systematic analysis of this enigma reveals that (1) $\beta$-globin exon 1 is bisected by a sharp border that separates NMD-activating from NMD-bypassing nonsense mutations and (2) the ability to bypass NMD depends on the ability to reinitiate translation at a downstream start codon. The data presented here thus reconcile the current mechanistic understanding of NMD with the observed failure of a class of nonsense mutations to activate this important mRNA quality-control pathway. Furthermore, our data uncover a reason why the position of a nonsense mutation alone does not suffice to predict the fate of the affected mRNA and its effect on protein expression.
\end{abstract}

Keywords: nonsense-mediated mRNA decay; NMD-resistant transcripts; premature termination; $\beta$-thalassemia; translation reinitiation

\section{INTRODUCTION}

Nonsense-mediated mRNA decay (NMD) is a post-transcriptional surveillance mechanism that degrades transcripts with nonsense mutations in their open reading frame (ORF). It has been estimated that nonsense mutations account for as much as $25 \%$ of all phenotypically rel-

\footnotetext{
${ }^{4}$ Present address: Institute for Genetics, University of Köln, 50674 Köln, Germany.

${ }^{5}$ Present address: Clinic of Psychiatry, Charite CBF, 14050 Berlin, Germany.

${ }^{6}$ Present address: Department of Pediatrics, Massachusetts General Hospital/Harvard Medical School, Boston, MA 02114, USA.

Reprint requests to: Andreas E. Kulozik, Department of Pediatric Oncology, Hematology and Immunology, University of Heidelberg, 69120 Heidelberg, Germany; e-mail: Andreas.Kulozik@med.uni-heidelberg.de; or Matthias W. Hentze, Molecular Medicine Partnership Unit, University of Heidelberg and European Molecular Biology Laboratory, Im Neuenheimer Feld 156, 69120 Heidelberg, Germany; e-mail: hentze@embl.de; fax: 496221 564580.

Article published online ahead of print. Article and publication date are at http://www.rnajournal.org/cgi/doi/10.1261/rna.2401811.
}

evant human mutations and thus underlie a multitude of human genetic diseases (Frischmeyer and Dietz 1999). $\beta$-thalassemia is the prototype disorder that documented the medical importance of NMD. The decreased abundance of mRNAs containing nonsense mutations, the signature phenomenon of NMD, was first discovered in $\beta$-thalassemia (Chang and Kan 1979). As a consequence, NMD limits the synthesis of C-terminally truncated polypeptides that might otherwise act in a dominant negative fashion. Interestingly, activation of NMD depends on the position of nonsense mutations. Mutations that reside at least 50 nt $5^{\prime}$ to an exon junction direct the affected mRNA to rapid decay. Such NMD-activating nonsense mutations result in the common recessive mode of inheritance with asymptomatic heterozygous carriers. In contrast, the less frequent nonsense mutations within the last exon do not activate NMD and yield a stable mRNA that directs the synthesis of C-terminally truncated polypeptides (Nagy and Maquat 1998; Thermann et al. 1998). These aberrant translation products act in a dominant negative fashion, resulting in a rare 
form of symptomatic heterozygous $\beta$-thalassemia that is characterized by a dominant mode of inheritance (Thein et al. 1990; Hall and Thein 1994). The majority of $\beta$-thalassemia carriers are thus protected by NMD from relevant disease manifestations. It has since been documented that this position-dependent effect of NMD applies more broadly to different genetic disorders (Holbrook et al. 2004; Khajavi et al. 2006; Kuzmiak and Maquat 2006; BenShachar et al. 2009; Bhuvanagiri et al. 2010). Mechanistically, the activation of NMD by nonsense mutations has been related to the interaction between the translation termination complex and a downstream exon junction complex (EJC), a situation that cannot arise with nonsense mutations in the $3^{\prime}$-terminal exon, thus explaining the failure of such mutations to activate NMD (for review, see Maquat 2004; Neu-Yilik and Kulozik 2008; Shyu et al. 2008; Rebbapragada and Lykke-Andersen 2009; Nicholson et al. 2010). The dependence of NMD on nuclear splicing is confirmed by the observation that most naturally or artificially intronless genes are resistant to NMD (Maquat and Li 2001; Neu-Yilik et al. 2001; Brocke et al. 2002). Recently, splicing-independent and EJC-independent examples of human NMD have also been described. In these cases, very long 3' UTRs together with an inappropriate spatial arrangement of the ribosome at the stop codon, the 3' UTR mRNP, and the poly(A) binding protein PABPC1 appear to be able to trigger NMD (Amrani et al. 2004; Buhler et al. 2006; Eberle et al. 2008; Singh et al. 2008). Such an aberrant (or "faux") 3' UTR is at least partially defined by the inappropriate distance between the termination codon and PABPC1, which is thought to prevent the termination promoting interaction between eRF3a and PABPC1 (Singh et al. 2008). Accordingly, PTCs located at the $3^{\prime}$ end of an ORF would not be recognized by NMD because the distance between such PTCs and PABPC1 is similar to the distance between the physiological termination codon and PABPC1 (Amrani et al. 2004; Eberle et al. 2008; Ivanov et al. 2008; Silva et al. 2008; Singh et al. 2008).

The analysis of $\beta$-globin NMD has also revealed examples of NMD-insensitive transcripts that cannot be explained by current models of NMD (Danckwardt et al. 2002; Stockklausner et al. 2006). Nonsense mutations in the first exon of the $\beta$-globin gene have been a particularly puzzling group of mutations that do not activate NMD (Romão et al. 2000; Inácio et al. 2004) and do not induce a symptomatic form of $\beta$-thalassemia. These mutations have been the subject of analysis of NMD resistance previously. The inability of first exon termination events to recruit the essential NMD-factor UPF1 and the potential proximity of the stabilizing Poly(A) binding protein $\mathrm{C} 1$ (PABPC1) to exon 1 termination sites within the mRNA closed loop formation during the initiating phase of translation have been hypothesized to play a mechanistic role (Silva et al. 2008). We now show that translation reinitiates after termination at these NMD-insensitive nonsense codons, thus leading to a bypass of NMD.

\section{RESULTS}

\section{$\beta$-globin exon 1 is bisected by a sharp border between nonsense codons that do or do not activate NMD}

In an earlier study, we determined the positional requirements of nonsense mutations in the second exon of the human $\beta$-globin gene and found that nonsense mutations that reside at least $50 \mathrm{nt} 5^{\prime}$ to the last exon junction in a spliced mRNA trigger NMD. NS26, the only nonsense mutation in the first exon included in this study, was found to be NMD-sensitive (Thermann et al. 1998). We have now systematically analyzed the NMD sensitivity of human $\beta$-globin transcripts with additional first exon nonsense mutations, which in principle would all be predicted to be NMD-sensitive. However, the abundance of transcripts with nonsense mutations from codons 2 through 23 revealed an only slight and gradual decrease from $90 \%$ to $70 \%$ of the expression of the normal allele, whereas mRNAs with a nonsense mutation at codon 26 or further downstream were down-modulated about fourfold to fivefold (Fig. 1A). These data confirm results in stably transfected murine erythroid cells and in stably and transiently transfected HeLa cells (Romão et al. 2000; Inácio et al. 2004), defining a sharp border for the position of nonsense mutations in the first exon that either do or do not direct mRNAs to NMD. Because all of the tested nonsense mutations are upstream of one or even two introns at a sufficient distance, the NMD insensitivity of most exon 1 nonsense mutations is surprising and not easily explained by current models of NMD (Neu-Yilik and Kulozik 2008; Maquat and Gong 2009; Rebbapragada and Lykke-Andersen 2009; Silva and Romão 2009; Bhuvanagiri et al. 2010; Nicholson et al. 2010).

We first considered the possibility that first exon nonsense mutations may display reduced NMD sensitivity, because first exons are spliced and defined in a manner that differs from internal exons (Berget 1995). Thus, we tested the hypothesis that exon $1 \mathrm{mRNPs}$ may preclude the identification of nonsense mutations by the NMD machinery. To this end, we transferred the wild-type gene and several nonsense-mutated alleles to a vector that provides a $5^{\prime}$ UTR intron (Fig. 1B). Thereby, the natural $\beta$-globin exon 1 (Fig. 1A) was transformed into a functional exon 2 without altering the sequence of the open reading frame (ORF). Although the introduction of an intron into the $5^{\prime}$ UTR reproducibly down-modulated the expression of transcripts with nonsense mutations at codons 3 through 20, this effect was quantitatively marginal (Fig. 1B) and also applied to the NMD-sensitive mutations at positions 26 and 39 (Fig. 1B), thus maintaining the sharp border between NMDactivating and NMD-bypassing nonsense mutations. These data indicate that the introduction of an intron into the $5^{\prime}$ UTR does not abrogate the NMD boundary in the first exon of the $\beta$-globin gene. 
A

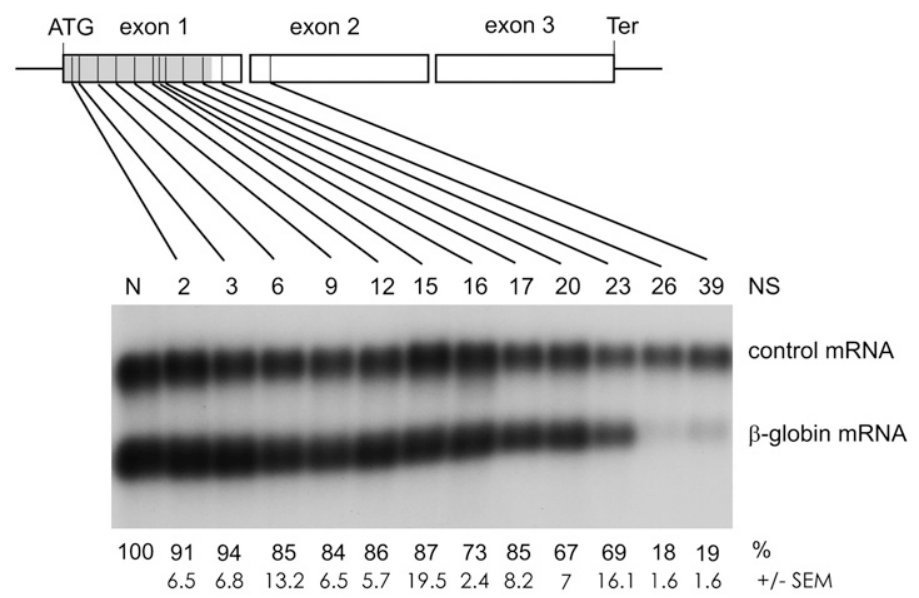

B
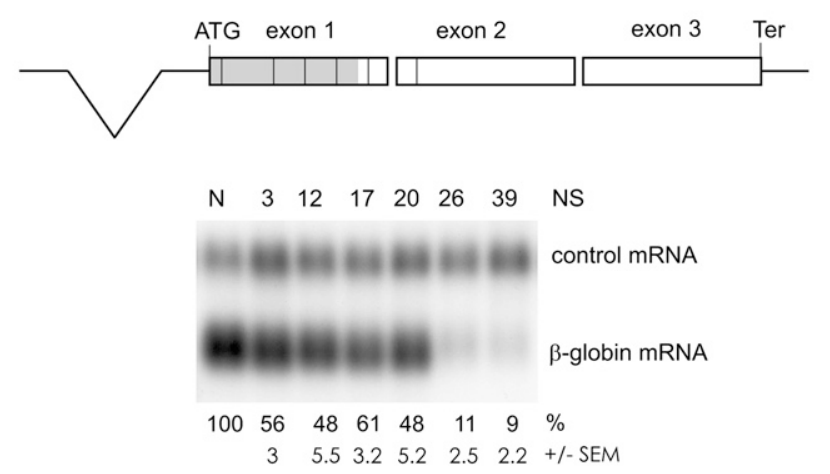

FIGURE 1. $\beta$-globin exon 1 is bisected by a sharp border between nonsense codons that do or do not activate NMD. Northern blot analysis of HeLa cells transiently transfected with normal $(\mathrm{N})$ or nonsense mutated $\beta$-globin genes with the endogenous 5' UTR and 3' UTR $(A)$ or with the $5^{\prime}$ UTR provided by the pCI-neo vector including a $5^{\prime}$ UTR intron $(B)$. Cells were cotransfected with a $\beta$-globin gene with extended second and third exons to control for transfection efficiency and loading. The positions of the nonsense mutations are depicted in the schematic representation in part $A$. The shaded region represents the NMD-resistant area in exon 1. Percentages (\%) are the mean of at least three independent experiments. (SEM) Standard error of the mean.

\section{Leaky termination or translational read-through does not account for the NMD resistance of early nonsense mutations}

NMD is a translation-dependent pathway (Belgrader et al. 1993; Carter et al. 1996; Thermann et al. 1998; Gudikote et al. 2005), and $\beta$-globin NMD requires the interaction between the translation termination complex and the EJC or other components of the $3^{\prime}$ mRNP (Le Hir et al. 2001; Kashima et al. 2006; Singh et al. 2008; Gehring et al. 2009). Nonsense suppression, translational read-through, or leaky termination can thus suppress NMD (Takeshita et al. 1984; Burke and Mogg 1985; Belgrader et al. 1993; Low and Berry 1996; Moriarty et al. 1998; Welch et al. 2007; Kaler et al. 2009; Finkel 2010). Therefore, we tested if leaky termination or translational read-through could account for the NMD resistance of early nonsense mutations in the $\beta$-globin gene. We created a double mutation with both, an NMDbypassing NS16 in the first exon and an NMD-activating
NS39 in the second exon (Fig. 2A). In case of nonsense suppression or leaky termination at NS16, this mRNA would be expected to be destabilized by the presence of the NS39 mutation. However, the mRNA with the double mutation was expressed at equally high levels as the transcripts with the NS16 mutation only (Fig. 2B, cf. lanes 2 and 3). In contrast, an mRNA containing NS39 alone was down-modulated as expected for NMD-sensitive transcripts (Fig. 2B, lane 4). Therefore, nonsense suppression and read-through cannot account for the NMD resistance of the exon 1 $\beta$-globin mutations.

\section{Mutation of Met55 rescues NMD sensitivity of early nonsense mutations}

In principle, reinitiation of translation of mRNAs with early nonsense mutations could bypass NMD. The $\beta$-globin gene contains only one in-frame start (Met) codon, which is located at position 55 of the ORF (Fig. 3A). The context of Met55 conforms to the Kozak consensus for efficient translation initiation (Kozak 1986). We mutated both the Met-codon itself and its context from GTT $\underline{A T G G G}$ to GTTCGCAA in the normal and several NMD-bypassing or NMD-activating $\beta$-globin alleles. For this and all following experiments, we used $\beta$-globin gene variants that contain a 5' UTR intron. Manipulating Met55 and its context profoundly increased, although did not completely restore, the NMD sensitivity of mRNAs with exon 1 nonsense mutations at positions 3 (NS3Met55Arg), 9 (NS9Met55Arg), and 16 (NS16Met55Arg). In contrast, the expression of the NMD-sensitive NS39 remained unchanged in the construct with the Met55 mutation (NS39Met55Arg) (Fig. 3B).

\section{Translation of $\beta$-globin $\mathrm{mRNAs}$ with exon 1 nonsense mutations reinitiates in exon 2}

The effect of the Met55 mutation suggested that reinitiation of translation induces NMD resistance of exon 1 nonsensemutated mRNAs. We tested this hypothesis directly by expressing the normal $\beta$-globin gene and several nonsense alleles that we furnished with a C-terminal venus-tag. In the absence of a nonsense mutation, this construct encodes a full-length fluorescent hybrid protein ( $\beta$-globinv), whereas 
A

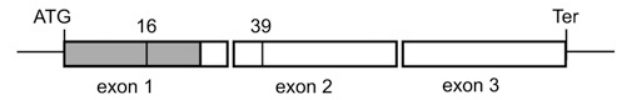

B

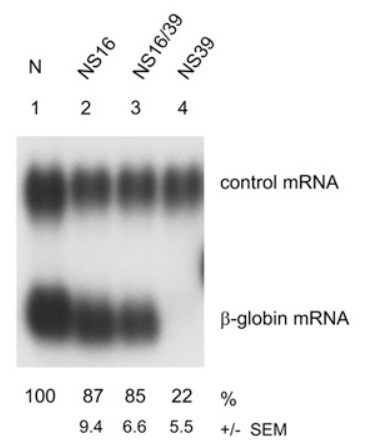

FIGURE 2. Read-through does not account for NMD insensitivity in exon 1. (A) Schematic representation of the $\beta$-globin gene with nonsense mutations at codons 16 and 39. (Shaded) NMD-resistant $5^{\prime}$ region in the $\beta$-globin mRNA. $(B)$ Northern blot analysis of total cytoplasmic RNA from HeLa cells transfected with expression plasmids for the normal $\beta$-globin gene or alleles that contain the indicated nonsense mutations. Percentages (\%) represent the mean of four independent experiments \pm SEM.

in-frame translation reinitiation following premature termination would be expected to result in a shorter hybrid protein (Met55 $\beta$-globinv) (Fig. 4A). In contrast, in case of active NMD, the mRNA would be degraded, thus reducing or abrogating green fluorescent hybrid protein synthesis. Expression of the venus tag is readily detected by fluorescence microscopy in cells transfected with the normal or the NS3-NS20 variants but not in cells transfected with the NS26 or NS39 alleles (Fig. 4B).

Immunoblot analysis, using an antiGFP antibody, demonstrates that cells transfected with the $\beta$-globin gene lacking a nonsense codon express the expected fusion protein of $44 \mathrm{kDa}$ (Fig. 4C, left panel, lane 1). In contrast, all NMD-resistant nonsense mutations including the double mutant NS16/39 predominantly express a $39-\mathrm{kDa}$ protein (Fig. 4C, lanes 2-6; Fig. 4D, lanes $2-4)$, while no protein is detected from cells transfected with the NMD-sensitive NS26 and NS39 alleles (Fig. 4C, lanes 7,8). The $39-\mathrm{kDa}$ protein corresponds to the expected size of the $\mathrm{N}$-terminally truncated fusion peptide when Met55 is used as a start codon. Finally, the specific role of Met55 was confirmed by mutational analysis. $\mathrm{Mu}-$ tation of Met55 to Arg55 prevents the expression of the $39-\mathrm{kDa}$ protein but not of the normal, full-length fusion protein (Fig. 4C, right panel).
Most of the NMD-resistant genes with nonsense mutations in the first exon appear not only to reinitiate at Met55 but also, albeit to a lesser extent, at one or even two earlier in-frame non-AUG codons (open arrows in Fig. 4C, lanes 2-5; Fig. 4D, lanes 2,3). Because the NS20 transcript does not use these minor reinitiation codons, they are likely to be situated in a position that is too short to support NS20 reinitiation. The double mutation NS16/39 also lacks these bands (Fig. 4D, lane 4), indicating that if translation reinitiates at this minor reinitiation codon, it subsequently runs into NS39. Mass spectrometry analysis after tryptic digestion of immunoprecipitated venus-tagged peptides resulting from $\beta$-globinvNS16 expression revealed a peptide with high signal intensity corresponding in mass to codons 19-31 with the sequence VNVDEVGGEALGR. Therefore, the minor reinitiation event after termination at NS16 uses either codon 17, 18, or 19 as start site. Most likely, codon 19 is being used for reinitiation, because this codon is a GUG and resides in a suboptimal but still adequate Kozak context (GgCAaGGUGaac). Moreover, we have inactivated the normal initiation codon to help identify alternative initiation events (Kozak 2002b). The mutation of the $\beta$-globin initiator AUG to a glycine codon shows that Met55 as well as the unknown non-AUG codons can be used as functional alternative translation start sites (Fig. 4E, lane 3). In fact, a weak band of the size of the Met55 $\beta$ globinv protein is also seen after transfection of a normal gene, indicating that the downstream initiation sites are most likely recognized by leaky scanning also in normal transcripts (arrow in Fig. 4D). This finding supports the notion that scanning is resumed following termination at
A

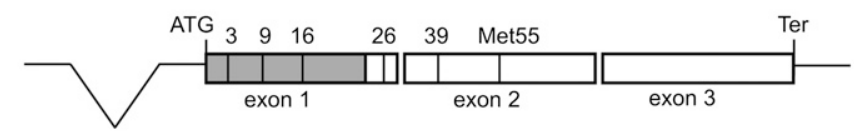

B

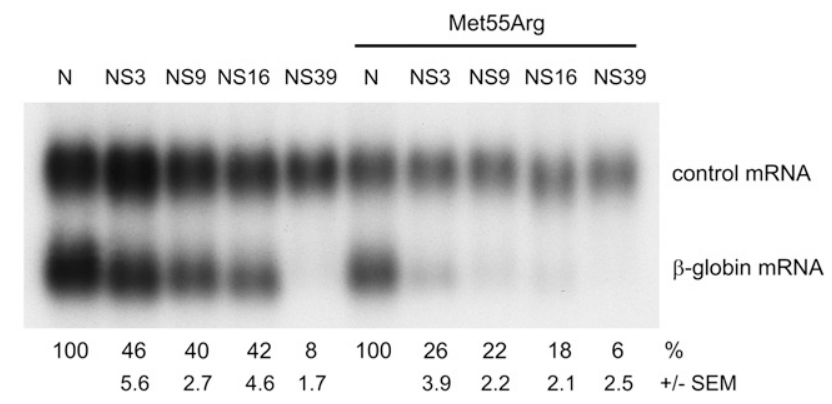

FIGURE 3. Mutation of methionine 55 restores NMD sensitivity of nonsense mutations in exon 1. (A) Schematic representation of the $\beta$-globin gene with nonsense mutations at positions 3, 9, 16, 26, and 39. (Shaded) NMD-resistant $5^{\prime}$ region. Met55 designates the position of the only in-frame methionine codon in the $\beta$-globin gene. $(B)$ Northern blot analysis of total cytoplasmic RNA from HeLa cells that were transfected with the expression plasmids for the normal $\beta$-globin gene or variants with nonsense mutations at the indicated positions and with or without the Met55Arg mutation. Percentages (\%) represent the mean of five independent experiments \pm SEM. 


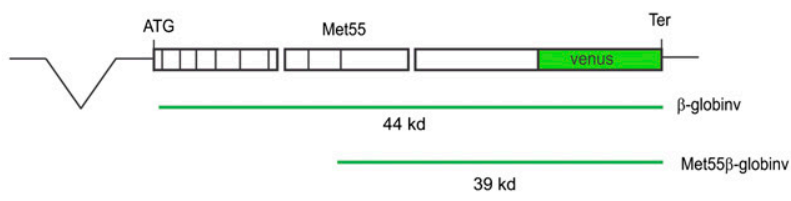

B
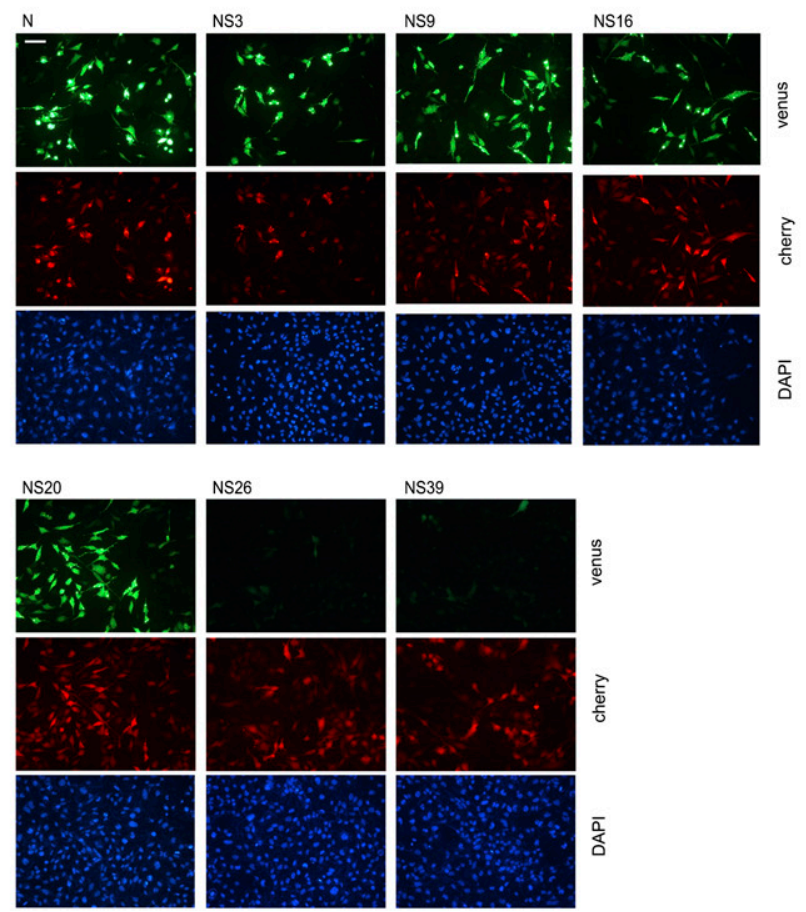

C

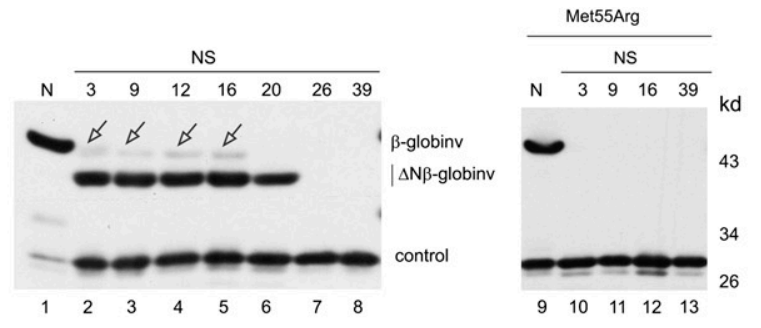

D

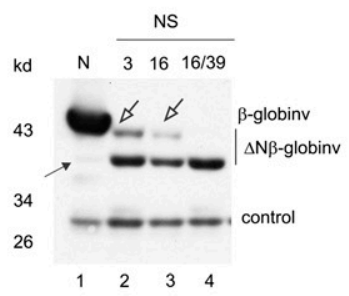

E

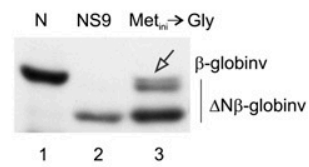

F
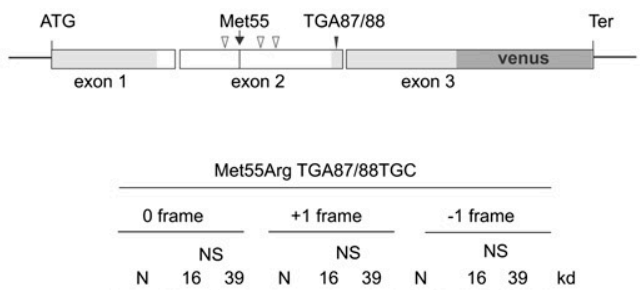

ß-globinv

TGA87/88TGC

$16 \quad 39$

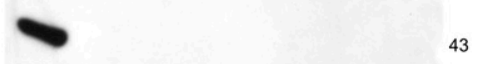

control

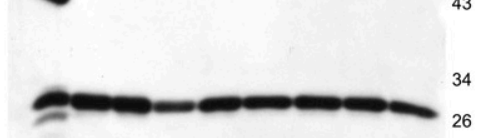

FIGURE 4. Translation reinitiation after termination codons in exon 1. (A) Schematic representation of the $\beta$-globinv gene, which contains a venus open reading frame (ORF) fused in-frame to the $3^{\prime}$ end of the $\beta$-globin sequence. (Bars) The positions of nonsense codons 3, 9, 12, 16, 20, 26, and 39, as well as of Met55. (Green lines under the scheme) Full-length or N-terminally truncated globinv proteins as expressed from a normal gene or after termination at a nonsense codon and reinitiation at Met55. (B) Fluorescence imaging of HeLa cells that were either transfected with normal or nonsense-mutated $\beta$-globinv variants and with a cherry expression plasmid as transfection efficiency control. DAPI staining serves as a reference for image exposure. Scale bar $=20 \mu \mathrm{m}$. (C) Immunoblot analysis of cytoplasmic lysates from HeLa cells that were transfected with normal or NS-mutated $\beta$-globinv genes (left panel) or variants where the Met55 codon was mutated as described in Figure 3 (right panel). Cotransfection of a YFP plasmid served as control. (Open arrows) The proteins that result from minor reinitiation at unknown non-AUG codons. All proteins were detected by a polyclonal anti-GFP antibody. (D) As $C$ but including the double mutant NS16/39. (Arrow) A protein that probably results from initiation in the normal transcript at Met55 by leaky scanning and that is absent in the Met55Arg variants. (E) Immunoblot analysis of normal or NS9 $\beta$-globinv gene expression, or the expression of a $\beta$-globinv gene variant where the normal initiation codon has been mutated to a glycine codon (Met ini $\left._{\rightarrow} \rightarrow \mathrm{Gly}\right)$. ( $F$, upper panel) Schematic representation of the positions of the Met55 codon and the three out-offrame AUG codons (open arrowheads) in exon 2 of the $\beta$-globin transcript as well as the position of the TGA87/88 codon in the 3' NMDinsensitive region (black arrowhead). (Light gray regions) The NMD-resistant areas in exons 1 and 3. (Lower panel) Immunoblot analysis of proteins produced by normal, NS16, or NS39 $\beta$-globinv genes that contain a Met55Arg TGA87/88TGC double mutation. Expression was analyzed in the normal translational reading frame, or alternatively in the +1 or the -1 frames of translation. The analysis of expression from the alternative frames was enabled by inserting one or two cytosine residues, respectively, immediately $5^{\prime}$ to the venus ORF.

an early nonsense codon and can lead to reinitiation at downstream sites. The cumulative effect of these additional reinitiation events may contribute to the residual NMD resistance of the nonsense-mutated Met55Arg transcripts.

In addition to Met55, exon 2 of the $\beta$-globin gene contains three out-of-frame AUG codons in the alternative +1 frame (Fig. 4F). The context of the AUG at position 52/53 in the +1 frame does not match the Kozak consensus and a
UGA resides at an NMD-competent position 8 codons further downstream. The AUGs at positions 63/64 and $73 / 74$ in the +1 frame match the Kozak consensus at one or both of the critical positions -3 and +4 , and translation reinitiation at these codons would terminate at a UGA at position $87 / 88$. Because this termination codon resides in the NMD-insensitive area in the vicinity of the last exon junction, termination at this site would not be expected to 
direct the mRNA to NMD. Together with reinitiation at the earlier non-AUG sites (see above), reinitiation at codons $63 / 64$ or $73 / 74$ could, in principle, add to the residual NMD resistance after mutation of Met55. To enable the investigation of reinitiation in the +1 and -1 reading frames, we inserted one ( +1 frame) or two ( -1 frame) cytosine residues, respectively, immediately $5^{\prime}$ to the venus ORF. In addition, to restrict reinitiation to Met55independent events, we mutated the TGA at position $87 / 88$ to TGC in the venus-tagged normal Met55Arg, the NS16Met55Arg, or the NS39Met55Arg genes in all three reading frames so that translation after reinitiation at AUG $63 / 64$ and/or 73/74 or at non-AUG-codons in-frame with TGA87/88TGC would terminate at the stop codon of the venus-tag. In immunoblots, using the GFP-antibody, no reinitiation event after NS16 or NS39 was detected in any of the three reading frames (Fig. 4F). Therefore, these additional out-of-frame AUG codons are not detectably used for reinitiation.

\section{Reinitiation capacity dominates over distance to the AUG in rescuing NMD sensitivity of early nonsense codons}

Considering that a block of reinitiation at Met55 does not completely restore NMD sensitivity (see Fig. 3), we next tested if manipulating the length of the ORF $5^{\prime}$ to the nonsense codon may synergize in rescuing NMD sensitivity of resistant alleles or may cause NMD resistance of sensitive alleles. To this end, we either deleted or inserted 10 codons in exon $1,5^{\prime}$ to codon 16 (Fig. 5A). Splicing fidelity at both exon junctions was confirmed by RT-PCR and sequencing of the splice products (data not shown).

The deletion of 10 codons between codons 2 and 11 in the first exon transforms the NS26 allele to an NS16 allele $(\Delta 2-11$ NS26 $\rightarrow 16)$ and the NS39 allele to an NS29 $(\Delta 2-$ 11 NS39 $\rightarrow 29$ ). This deletion causes the loss of NMD sensitivity of NS26, suggesting that the distance to the initiation codon may be a critical determinant for susceptibility to NMD (Fig. 5B). Deletion of these 10 codons in the NS16 mutant $(\mathrm{NS16} \rightarrow 6)$ does not display an effect on its NMD resistance. However, the NS39 $\rightarrow 29$ mRNA also loses its NMD sensitivity, which indicates that the distance between the AUG and the nonsense codon is not a simple parameter for NMD efficiency. Interestingly, the 30-bp deletion results in reinitiation at Met55 in both, the NS26 $\rightarrow 16$ and the NS39 $\rightarrow 29$ constructs, thus explaining their loss of NMD sensitivity (Fig. 5C; Supplemental Fig. 1). To investigate reinitiation in the other reading frames, we mutated, in the normal $\Delta 2-11$ gene and in the $\Delta 2$ 11 NS16 $\rightarrow 6$ and NS39 $\rightarrow 29$ variants, the Met55 codon as well as the TGA at position $87 / 88$ as described for Figure $4 \mathrm{~F}$. Both fluorescence microscopy and immunoblotting revealed that some reinitiation also takes place in the +1 reading frame (Supplemental Figs. 1, 2, lanes 6,7 and
A

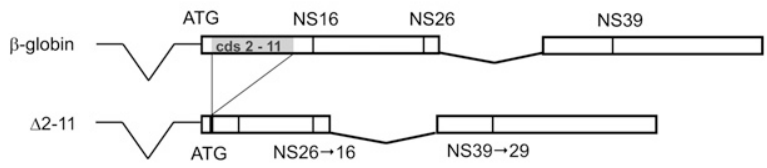

B

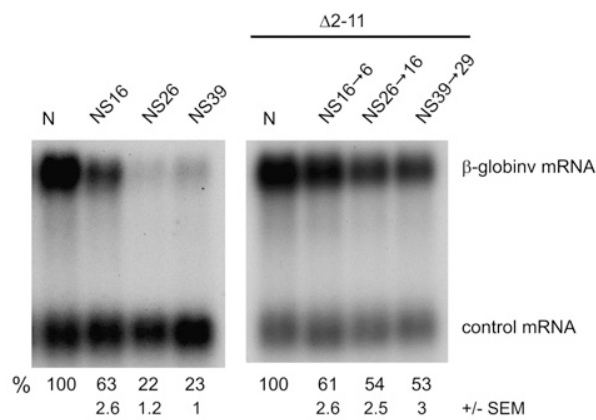

C

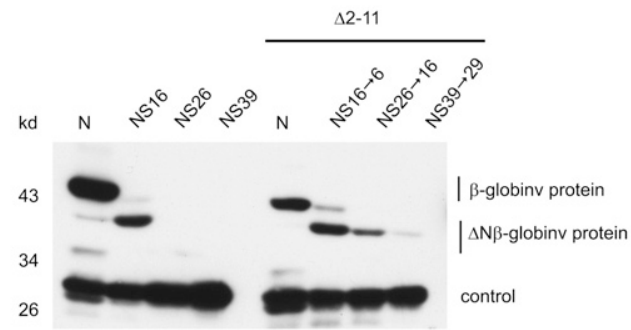

FIGURE 5. Shortening the distance between the initiation codon and the nonsense codon reduces NMD sensitivity by inducing reinitiation of translation. (A) Schematic representation of exons 1 and 2 of the $\beta$-globinv gene series of constructs and variants with in-frame deletions of codons 2 through $11(\Delta 2-11)$ and with nonsense mutations at positions 16,26 , or 39 . Numbers refer to the position in the undeleted gene. Numbers behind arrows indicate the position of the nonsense mutations with respect to the initiator AUG in the deletion constructs. $(B)$ Northern blot analysis of transcripts expressed in HeLa cells from the $\beta$-globinv construct series or the $\Delta 2$-11variants. (C) Immunoblot analysis of proteins expressed from the constructs described in $A$ and $B$.

16,17), which may contribute to the NMD resistance of the NS26 $\rightarrow 16$ and the NS39 $\rightarrow 29$ transcripts. These proteins are probably unstable, because the intensity of the respective bands in the immunoblot is enhanced by treatment with MG132 (cf. Supplemental Fig. 2, lanes 6,7 and 16,17$)$. The ability to reinitiate in the +1 frame likely results from the shortening of the uORF, because we did not observe any reinitiation in this frame in the undeleted constructs (Fig. 4F).

In a complementary experiment, we inserted 10 codons between codons 2 and 3 of exon 1, thereby increasing the distance between the NMD-resistant NS16 (NS16 $\rightarrow$ 26) and the AUG to 26 codons, a position that was expected to be NMD-competent if distance to the AUG were the dominant component of NMD sensitivity (Fig. 6A). Yet, the Northern blot shows that the ins $2 / 3 \mathrm{NS} 16 \rightarrow 26 \mathrm{mRNA}$ remains NMD-resistant (Fig. 6B) likely by retaining its reinitiation capacity (Fig. 6C, lane 6; Supplemental Fig. 3). Since the uORF lengths of the NMD-resistant ins2/3NS16 $\rightarrow 26$ 
A

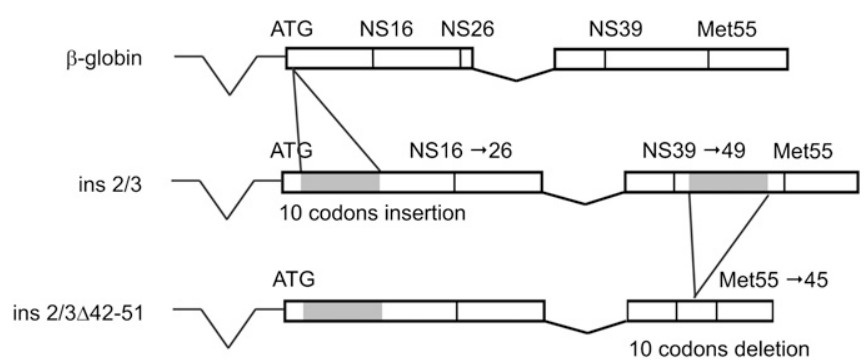

B

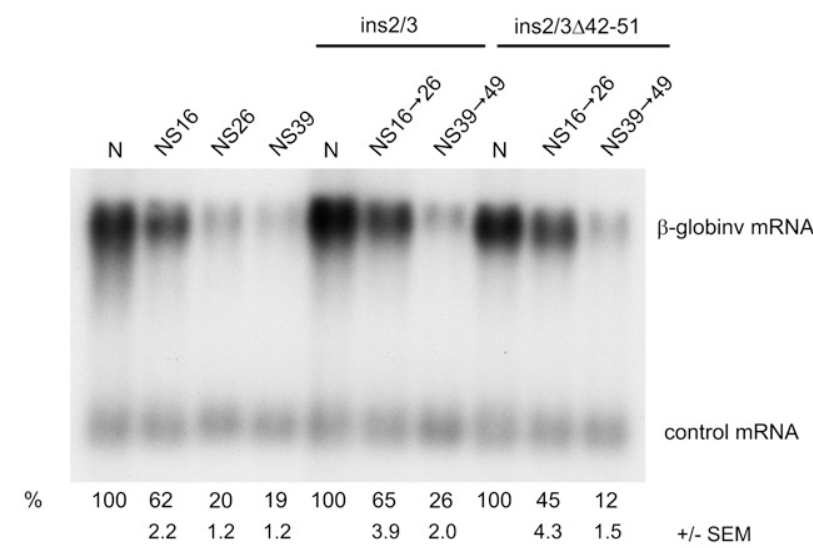

C

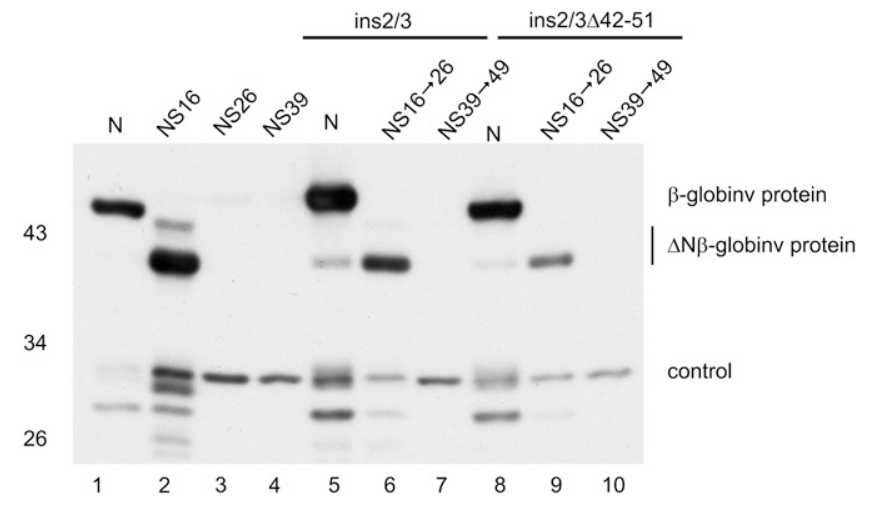

FIGURE 6. Increasing the distance between the initiation codon and the nonsense codon does not restore NMD sensitivity when translation reinitiation is maintained. (A) Schematic representation of the $5^{\prime}$ part of the $\beta$-globinv gene series of constructs and variants with nonsense mutations at positions 16,26 , or 39 and with in-frame insertions of 10 codons between codons 2 and 3 (ins $2 / 3$ ) in exon 1 . In the ins $2 / 3 \Delta 42-51$ series of constructs in addition, codons 42 and 51 were deleted. Numbers behind the arrows indicate the position of the nonsense mutations with respect to the initiator AUG in the ins $2 / 3$ and in the ins $2 / 3 \Delta 42$ 51 constructs. $(B)$ Northern blot analysis of transcripts expressed from the $\beta$-globinv construct series or the variants with the ins $2 / 3$ insertion and with the additional deletion of codons 42-51. Percentages (\%) are means of at least five independent experiments \pm SEM. $(C)$ Immunoblot analysis of proteins expressed from the constructs described in $A$ and $B$.

transcript and of the $\beta$-globinvNS26 transcript are identical, this result was surprising. We hypothesized that the intercistronic distance (ICD) of the ins $2 / 3 \mathrm{NS} 16 \rightarrow 26$ mRNA, which is $30 \mathrm{nt}$ longer than in the $\beta$-globinvNS26 transcript, may enable the retrieval of lost reinitiation capacity. Therefore, we deleted codons $42-51$ in exon 2 of the normal ins $2 / 3$ gene and the ins2/3NS16 $\rightarrow 26$ and the ins2/3NS39 $\rightarrow 49$ alleles. The Met55 reinitiation codon was thus moved to a position with respect to the NS codons $16 \rightarrow 26$ and $39 \rightarrow 49$ that is identical to those of the $\beta$-globinvNS26 and NS39 genes. Surprisingly, the ins2/ $3 \Delta 42-51 \mathrm{NS} 16 \rightarrow 26 \mathrm{mRNA}$ is still reinitiation-competent albeit with less efficiency than the ins $2 / 3 \mathrm{NS} 16 \rightarrow 26 \mathrm{mRNA}$ (Fig. 6C, lanes 6,9; Supplemental Fig. $3 \mathrm{~B}, \mathrm{C})$, and the mRNA expression level mirrors the protein expression level (Fig. $6 \mathrm{~B})$. Taken together, the insertion and deletion experiments reveal that not the distance to the AUG but the ability to promote reinitiation after termination is the major determinant of NMD resistance of mRNAs with nonsense mutations in the first exon of the human $\beta$-globin gene.

\section{DISCUSSION}

NMD represents one of the major quality-control pathways of the cell, whose medical implications are exemplified by $\beta$-thalassemias. In most described cases, NMD is splicing-dependent, always translation-dependent, and relies either on the interaction of the translation apparatus with the exon junction complexes or on the distance between the PTC and PABPC1 (for review, see Maquat 2004; Neu-Yilik and Kulozik 2008; Shyu et al. 2008; Rebbapragada and Lykke-Andersen 2009; Bhuvanagiri et al. 2010; Nicholson et al. 2010). Based on this feature of NMD, it has been straightforward to conceptualize the NMD resistance of mRNAs with a nonsense mutation in the $3^{\prime}$-terminal exon, which has been exemplified by the dominant $\beta$-thalassemia mutations in exon 3 of the $\beta$-globin gene (Thein et al. 1990; Hall and Thein 1994). The NMD resistance of nonsense mutations in the first exon of the $\beta$-globin gene and also of numerous other genes has been much more difficult to understand (for review, see Holbrook et al. 2004; Neu-Yilik and Kulozik 2008). In $\beta$-globin, the proximity of the termination event to the AUG and to the $3^{\prime} \mathrm{mRNP}$ including the poly $(\mathrm{A})$ binding protein $\mathrm{C} 1$ within the mRNA 
"closed loop" formation (Wells et al. 1998) has been interpreted to mimic a proper position of termination, thus bypassing NMD (Eberle et al. 2008; Ivanov et al. 2008; Silva et al. 2008; Singh et al. 2008). In other cases, reinitiation of translation has been shown to play an important role (Zhang and Maquat 1997; Perrin-Vidoz et al. 2002; Denecke et al. 2004; Buisson et al. 2006; Paulsen et al. 2006).

In this study, we investigated exon definition, translational read-through, and reinitiation as candidate mechanisms to account for the NMD resistance of early nonsense mutations in the human $\beta$-globin gene. Using a $\beta$-globin variant with both an NMD-resistant NS16 and an NMD-sensitive NS39 in cis, we demonstrate that readthrough can be excluded as a cause for NMD evasion. This is in accordance with a similar result by Inácio et al. (2004), who used an NS15/39 double mutant to investigate if proximity to the AUG dominates the 50-54 nt rule. In further experiments, we show that the in-frame downstream AUG codon at position 55 serves as a reinitiation site of $\beta$-globin mRNAs with first exon nonsense mutations and that this reinitiation bypasses NMD. The ability to reinitiate after early termination in the $\beta$-globin gene follows the rules known for reinitiation in eukaryotes, namely, that sufficiently short upstream open reading frames (uORFs) and a sufficiently long intercistronic distance (ICD) determine the reinitiation efficiency (Kozak 1987). The combination of long uORFs and short ICDs as in the $\beta$-globin NS26 and NS39 transcripts precludes reinitiation, whereas the short uORFs in combination with long ICDs in NMD-bypassing exon 1 nonsense mutants support efficient reinitiation at Met55. The deletion experiments show that a reinitiation-permissive uORF length can compensate for an unfavorable ICD length. This interpretation is supported by data from a previous study in which shortening the uORF of NS39 by 24 codons induced NMD resistance and the insertion of 24 heterologous codons into the NS15 uORF-induced NMD sensitivity of the respective transcripts (Inácio et al. 2004). On the other hand, lengthening the uORF of the reinitiation-competent NS16 by 10 to 26 codons had only limited adverse effects on transcript abundance and reinitiation. We initially hypothesized that the long ICD that followed the now relatively long uORF may enable the retrieval of lost reinitiation capacity. However, shortening this ICD by $30 \mathrm{nt}$ clearly reduced but did not eliminate the reinitiation competence of the transcript carrying the NS16 $\rightarrow 26$ mutation. Importantly, neither lengthening the uORF nor shortening the ICD in this construct series had a major influence on transcript abundance. Furthermore, the $\Delta 2-11$ NS39 $\rightarrow 29$ transcript supports reinitiation despite its relatively long uORF and relatively short ICD. These results thus confirm earlier observations indicating that the spatial relationship of the uORF and ICD length are not rigid determinants of reinitiation in higher eukaryotes (Kozak 2001, 2002a; Poyry et al. 2004). Several studies have shown that (1) there is no strict answer as to which uORF size is reinitiation-compatible and that (2) elongation velocity rather than the uORF length determines reinitiation efficiency (Kozak 2001; Poyry et al. 2004). Therefore, we suggest that both the deletion of codons $2-11$ and the insertion of the $30 \mathrm{nt}$ between codons 2 and 3 accelerate the elongation rate across exon 1 and thus promote reinitiation at Met55 even in transcripts with longer uORFs.

Furthermore, a recent study demonstrated that rare read-through events are sufficient to rescue transcripts from NMD (Hogg and Goff 2010), probably because a single event of either read-through or reinitiation suffices to remodel the RNP structure of a potentially NMDsensitive transcript. This would explain the high expression levels of the $\Delta 2-11$ NS39 $\rightarrow 29$ and ins2/3 $\Delta 42-51$ NS16 $\rightarrow 26$ transcripts. Formally, the detection of the proteins initiated from $3^{\prime}$ start codons in the $\Delta 2-11$ NS26 $\rightarrow 16$, and especially the $\Delta 2-11$ NS39 $\rightarrow 29$ transcripts could also be the result and not the cause of their high mRNA expression levels. However, this is unlikely because the abundance of the $\Delta 2-11 \mathrm{NS} 16 \rightarrow 6, \quad \mathrm{~N} 26 \rightarrow 16$, and NS39 $\rightarrow 29$ mRNAs is similar, which would then predict that the reinitiation rate at Met55 should also be the same but clearly is not (Fig. 5C). Therefore, we conclude that all NMD-resistant $\beta$-globin transcripts with nonsense mutations featured the capacity to reinitiate translation after termination and that reinitiation is the cause of their NMD insensitivity.

Some of our findings are in conflict with earlier reports (Romão et al. 2000; Inácio et al. 2004; Silva et al. 2008) that found no influence of simultaneous point mutations of Met55 and the two out-of-frame methionine codons 63/64 and 73/74 on the expression level of an NS15 allele in MEL and HeLa cells. In all of our constructs the Met55 codon is used as the main reinitiation codon. In contrast to the study of Inácio et al. (2004), where the Met55 AUG codon was point-mutated to AUA, we not only changed the Met55 codon at all three positions from AUG to CGC but also mutated the crucial position +4 of the Kozak consensus sequence (Fig. 3). Because of the ability of the $\beta$-globin gene to use non-AUG codons for initiation, we suggest that the different results may be explained by the point mutations inserted by Inácio et al. not having completely inactivated the reinitiation capacity of the transcripts. Importantly, using venus-tagged constructs, our data demonstrate the restoration of NMD sensitivity after the elimination of Met55 as a reinitiation codon. Furthermore, the data presented here also unequivocally show that $\mathrm{N}$-terminally truncated $\beta$-globin hybrid proteins are produced by all NMD-resistant transcripts with early nonsense mutations. In this respect, the data of Inácio et al. are difficult to interpret conclusively, because they do not include protein expression data (Inácio et al. 2004, 2007).

Abrogation of the reinitiation capacity can also explain why in the study by Silva et al. (2008) the insertion of a classical swine fever virus internal ribosomal entry site (CSFV IRES) 
into the 5' UTR or of a pseudoknot structure into the ORF of an AUG-proximal $\beta$-globin NS gene converted the mRNA from being NMD-resistant to NMD-sensitive. CSFV IRESdirected translational initiation is independent of the eIF4 initiation factor complex (Pestova et al. 1998; Poyry et al. 2004). Likewise, the insertion of a pseudoknot into the $5^{\prime}$ part of an ORF decelerates translation velocity, promoting the loss of eIF4 (Kozak 2001). Therefore, the investigators hypothesized that the initiating ribosome maintains the eIF4GPABPC1 interaction for a short time, thereby bringing PABPC1 into the vicinity of early nonsense codons, a situation that they had shown by PABPC1 tethering experiments to stabilize NMD-sensitive transcripts. However, the results of both manipulations are equally consistent with a loss of reinitiation capacity. The CSFV IRES is unable to support reinitiation after the translation of a uORF (Poyry et al. 2004). Moreover, as mentioned above, the velocity of translation rather than the uORF length is critical for the ability to reinitiate at a $3^{\prime}$ AUG (Kozak 2001; Poyry et al. 2004) and therefore slowing down translation by the insertion of a pseudoknot $5^{\prime}$ to an NS-codon may transform the respective transcript from NMD-bypassing to NMD-sensitive by abolishing reinitiation further downstream.

Considering that $\beta$-globin mRNAs with exon 1 nonsense mutations direct the synthesis of non-functional $\beta$-globin fragments, it is interesting that such mutations do not cause dominant thalassemia in a similar fashion as nonsense mutations in exon $3 \mathrm{do}$. While this question is still unresolved, the data presented here suggest that $\mathrm{N}$-terminally truncated $\beta$-globin fragments are less toxic than C-terminally truncated fragments. Furthermore, it must be noted that heterozygotes for the $\beta$-globin initiation codon mutation show a more severe hematological phenotype than those with mutations further 3 ', indicating that the synthesis of $\mathrm{N}$-terminally truncated $\beta$-globin fragments may also have a subtle dominant negative effect (Waye et al. 1997).

In other genes, $\mathrm{N}$-terminally truncated protein fragments directed by reinitiating mRNAs with $5^{\prime}$ nonsense mutations can assume significant residual function, thus showing a milder clinical phenotype than mutations more $3^{\prime}$ or null mutations. These include the genes for RAG1 (Santagata et al. 2000), NBS1 (Maser et al. 2001), DAX1 (Ozisik et al. 2003), ATRX (Howard et al. 2004), FOXL2 (Moumne et al. 2005), BRCA1 (Buisson et al. 2006), ATP7A (Paulsen et al. 2006), RB1 (Sanchez-Sanchez et al. 2007), NEMO (Puel et al. 2006), I $\kappa \alpha$ (McDonald et al. 2007), PHOX2B (Trochet et al. 2009), DMD (Gurvich et al. 2009), and FAC (Yamashita et al. 1996). A notable exception is the expression of a $\Delta \mathrm{N} 25$ isoform of TP63 expressed from an allele with a nonsense mutation at codon 11 that manifests dominant effects and is associated with a Rapp-Hodkin/ Hay-Wells like syndrome (Rinne et al. 2008).

Taken together, this work demonstrates that a complex interplay between the length of the first open reading frame, the intercistronic distance, and other as yet un- known parameters can determine the reinitiation competence at AUG and non-AUG codons after termination at a $5^{\prime}$-proximal nonsense codon. Therefore, reinitiation is likely a frequent cause for bypassing NMD. Moreover, the failure to activate NMD and the ability to reinitiate translation further downstream may underlie some of the hitherto unexplained heterogeneity of disease phenotypes caused by nonsense mutations and adds an additional layer of complexity to the impact of NMD on human genetic disease.

\section{MATERIALS AND METHODS}

\section{Constructs}

The human $\beta$-globin constructs with a normal ORF or with a nonsense codon at position 26 or position 39 used for the experiments shown in Figures 1, 2, and 3 have been described previously (Thermann et al. 1998; Neu-Yilik et al. 2001). Nonsense mutations at positions $2,3,5,6,9,12,15,16,17,20$, and 23 were introduced by site-directed mutagenesis. The constructs used for the experiments shown in Figure 1A and in Figure 2 contain a 4.4-kb $\beta$-globin gene including the $\beta$-globin promoter, the $\beta$-globin UTRs, and a linked SV40 enhancer inserted as an NotI fragment into pBluescriptSK II+ (Stratagene). The constructs used for the experiments shown in Figure $1 \mathrm{~B}$ and Figure 3 contain a genomic $\beta$-globin gene fragment extending from the physiological translation initiation codon to the translation termination codon inserted into the pCIneo vector (Promega) at the NheI and XhoI sites of the polylinker. The pCIneobased constructs were furnished with a venus-tag by inserting the venus ORF (Nagai et al. 2002) without its translation initiation codon in-frame with the $\beta$-globin ORF into the XbaI and NotI sites of the polylinker. The physiological termination codon of the $\beta$-globin ORF was deleted by site-directed mutagenesis. The deletion constructs in Figure 5 were generated from the respective $\beta$-globin-venus constructs by in-frame deletion of codons 2 through 11. The constructs used for Figure 6 were generated by insertion of codons $120-129$ from the $\beta$-globin exon 3 in-frame between codons 2 and 3 of the respective $\beta$-globin-venus ( $\beta$-globinv) constructs. The $\Delta 42-51$ variants of these constructs were generated by in-frame deletion of codons 42 (now 52) through 51 (now 61) in exon 2. The frameshifted genes used for Figure 4E and Supplemental Figures 1 and 2 were generated by insertion of one (+1 frame) or two ( -1 frame) cytosine residues, respectively, immediately $5^{\prime}$ to the venus ORF. The Met $_{\text {ini }} \rightarrow$ Gly mutation, the Met55Arg mutations, and the TGA87/88TGC mutations were generated by site-directed mutagenesis. All constructs were sequenced prior to use. Splicing fidelity of mRNAs carrying insertions or deletions was confirmed by sequencing of cDNAs generated by RT-PCR from total cytoplasmic RNA after transient transfections.

\section{Cell culture and transfections}

HeLa cells were grown in DMEM and transfected in 6-cm plates by calcium phosphate precipitation with standard methods using $1.5-3 \mu \mathrm{g}$ of the test plasmids, $0.8-1.5 \mu \mathrm{g}$ of the control plasmid, and $0.8 \mu \mathrm{g}$ of a YFP or a cherry expression vector. For the venustagged constructs, a normal human $\beta$-globin gene in the pBluescript 
vector served as transfection efficiency control. For the untagged reporters, the wt $+300+\mathrm{e} 3$ plasmid (Gehring et al. 2003) was used for the same purpose. For the experiment shown in Supplemental Figure 2, transiently transfected cells were treated with $25 \mu \mathrm{M}$ MG132 (Calbiochem) for $5 \mathrm{~h}$ before harvest.

\section{RNA analysis}

Total cytoplasmic RNA was isolated from homogenized cells as previously described (Gehring et al. 2003). Northern blot analysis was performed with $1.5-5 \mu \mathrm{g}$ of total cytoplasmic RNA according to standard protocols.

\section{Signal quantification}

Radioactive signals were quantified by PhosphorImaging in an FLA-3000 fluorescent image analyzer (Raytest; Fujifilm). Expression levels were calculated after correction for transfection efficiency. Mean values and standard error of the mean (SEM) were calculated from at least three independent experiments.

\section{Protein analysis}

Immunoblotting was performed as described (Gehring et al. 2003). $\beta$-globinv proteins were visualized using a GFP-specific antibody (Abnova). For the preparation of mass spectrometry (Core Facility for Mass Spectrometry and Proteomics, ZMBH, Heidelberg) analysis of venus-tagged $\beta$-globin polypeptides, cells were lysed and bound to GFP-Trap ${ }^{\circledR}$-A beads (Chromotek) according to the instructions of the manufacturer, separated on a $10 \%$ SDS-PAGE gel, and silver-stained.

\section{Fluorescence microscopy}

For fluorescence microscopy of $\beta$-globinv proteins, cells were transfected on glass coverslips in 6-well plates with $3 \mu \mathrm{g}$ of the venus-tagged reporter plasmids and $0.8 \mu \mathrm{g}$ of a cherry expression vector, which served as a transfection efficiency control. The transfected cells were fixed for $30 \mathrm{~min}$ in $4 \%$ paraformaldehyde at room temperature, stained with DAPI (Sigma) at $0.625 \mu \mathrm{g} / \mathrm{mL}$ in PBS, and mounted with Mowiol 4-88 mounting medium (Calbiochem). Images were captured using a $20 \times / 0.35$ Plan objective on a Leica DMI 4000B inverted microscope (Leica Microsystems). GFP signals were visualized using the L5 channel and cherry signals using the N2.1 channel at $200 \times$ magnification. The camera settings were identical for all images displayed in Figure 4 and Supplemental Figures 1 and 3. The Leica Application Suite software was used for image processing.

\section{SUPPLEMENTAL MATERIAL}

Supplemental material is available for this article.

\section{ACKNOWLEDGMENTS}

We thank T. Ruppert (Core Facility for Mass Spectrometry and Proteomics, ZMBH, Heidelberg) for mass spectrometry analysis. G.N.-Y., B.A., S.B., and H.P. performed experiments. G.N.-Y. and N.H.G. analyzed the results and made the figures. G.N.-Y., N.H.G., A.E.K., and M.W.H. designed the research and wrote the paper. This work was supported financially by the Deutsche Forschungsgemeinschaft.

Received August 2, 2010; accepted January 31, 2011.

\section{REFERENCES}

Amrani N, Ganesan R, Kervestin S, Mangus DA, Ghosh S, Jacobson A. 2004. A faux $3^{\prime}$-UTR promotes aberrant termination and triggers nonsense-mediated mRNA decay. Nature 432: 112-118.

Belgrader P, Cheng J, Maquat LE. 1993. Evidence to implicate translation by ribosomes in the mechanism by which nonsense codons reduce the nuclear level of human triosephosphate isomerase mRNA. Proc Natl Acad Sci 90: 482-486.

Ben-Shachar S, Khajavi M, Withers MA, Shaw CA, van Bokhoven H, Brunner HG, Lupski JR. 2009. Dominant versus recessive traits conveyed by allelic mutations-to what extent is nonsensemediated decay involved? Clin Genet 75: 394-400.

Berget SM. 1995. Exon recognition in vertebrate splicing. J Biol Chem 270: $2411-2414$.

Bhuvanagiri M, Schlitter AM, Hentze MW, Kulozik AE. 2010. NMD: RNA biology meets human genetic medicine. Biochem J 430: 365377.

Brocke KS, Neu-Yilik G, Gehring NH, Hentze MW, Kulozik AE. 2002. The human intronless melanocortin 4-receptor gene is NMD insensitive. Hum Mol Genet 11: 331-335.

Buhler M, Steiner S, Mohn F, Paillusson A, Muhlemann O. 2006. EJCindependent degradation of nonsense immunoglobulin-mu mRNA depends on 3' UTR length. Nat Struct Mol Biol 13: 462-464.

Buisson M, Anczukow O, Zetoune AB, Ware MD, Mazoyer S. 2006. The 185delAG mutation (c.68_69delAG) in the BRCA1 gene triggers translation reinitiation at a downstream AUG codon. Hum Mutat 27: 1024-1029.

Burke JF, Mogg AE. 1985. Suppression of a nonsense mutation in mammalian cells in vivo by the aminoglycoside antibiotics G-418 and paromomycin. Nucleic Acids Res 13: 6265-6272.

Carter MS, Li S, Wilkinson MF. 1996. A splicing-dependent regulatory mechanism that detects translation signals. EMBO J 15: 5965-5975.

Chang JC, Kan YW. 1979. Beta 0 thalassemia, a nonsense mutation in man. Proc Natl Acad Sci 76: 2886-2889.

Danckwardt S, Neu-Yilik G, Thermann R, Frede U, Hentze MW, Kulozik AE. 2002. Abnormally spliced $\beta$-globin mRNAs: a single point mutation generates transcripts sensitive and insensitive to nonsense-mediated mRNA decay. Blood 99: 1811-1816.

Denecke J, Kranz C, Kemming D, Koch HG, Marquardt T. 2004. An activated $5^{\prime}$ cryptic splice site in the human ALG3 gene generates a premature termination codon insensitive to nonsense-mediated mRNA decay in a new case of congenital disorder of glycosylation type Id (CDG-Id). Hum Mutat 23: 477-486.

Eberle AB, Stalder L, Mathys H, Orozco RZ, Muhlemann O. 2008. Posttranscriptional gene regulation by spatial rearrangement of the 3' untranslated region. PLoS Biol 6: e92. doi: 10.1371/journal. pbio.0060092.

Finkel RS. 2010. Read-through strategies for suppression of nonsense mutations in Duchenne/Becker muscular dystrophy: Aminoglycosides and ataluren (PTC124). J Child Neurol 25: 1158-1164.

Frischmeyer PA, Dietz HC. 1999. Nonsense-mediated mRNA decay in health and disease. Hum Mol Genet 8: 1893-1900.

Gehring NH, Neu-Yilik G, Schell T, Hentze MW, Kulozik AE. 2003. Y14 and hUpf3b form an NMD-activating complex. Mol Cell 11: 939-949.

Gehring NH, Lamprinaki S, Hentze MW, Kulozik AE. 2009. The hierarchy of exon-junction complex assembly by the spliceosome explains key features of mammalian nonsense-mediated mRNA decay. PLoS Biol 7: e1000120. doi: 10.1371/journal.pbio.1000120.

Gudikote JP, Imam JS, Garcia RF, Wilkinson MF. 2005. RNA splicing promotes translation and RNA surveillance. Nat Struct Mol Biol 12: $801-809$. 
Gurvich OL, Maiti B, Weiss RB, Aggarwal G, Howard MT, Flanigan KM. 2009. DMD exon 1 truncating point mutations: amelioration of phenotype by alternative translation initiation in exon 6. Hum Mutat 30: 633-640.

Hall GW, Thein S. 1994. Nonsense codon mutations in the terminal exon of the $\beta$-globin gene are not associated with a reduction in $\beta$-mRNA accumulation: a mechanism for the phenotype of dominant $\beta$-thalassemia. Blood 83: 2031-2037.

Hogg JR, Goff SP. 2010. Upf1 senses 3'UTR length to potentiate mRNA decay. Cell 143: 379-389.

Holbrook JA, Neu-Yilik G, Hentze MW, Kulozik AE. 2004. Nonsensemediated decay approaches the clinic. Nat Genet 36: 801-808.

Howard MT, Malik N, Anderson CB, Voskuil JL, Atkins JF, Gibbons RJ. 2004. Attenuation of an amino-terminal premature stop codon mutation in the ATRX gene by an alternative mode of translational initiation. J Med Genet 41: 951-956.

Inácio A, Silva AL, Pinto J, Ji X, Morgado A, Almeida F, Faustino P, Lavinha J, Liebhaber SA, Romão L. 2004. Nonsense mutations in close proximity to the initiation codon fail to trigger full nonsensemediated mRNA decay. J Biol Chem 279: 32170-32180.

Inácio A, Silva AL, Morgado A, Pereira FJ, Lavinha J, Romão L. 2007. Comment on 'Nonsense-mediated mRNA decay modulates clinical outcome of genetic disease'. Eur J Hum Genet 15: 533-534; author reply 534 .

Ivanov PV, Gehring NH, Kunz JB, Hentze MW, Kulozik AE. 2008. Interactions between UPF1, eRFs, PABP and the exon junction complex suggest an integrated model for mammalian NMD pathways. EMBO J 27: 736-747.

Kaler SG, Tang J, Donsante A, Kaneski CR. 2009. Translational readthrough of a nonsense mutation in ATP7A impacts treatment outcome in Menkes disease. Ann Neurol 65: 108-113.

Kashima I, Yamashita A, Izumi N, Kataoka N, Morishita R, Hoshino S, Ohno M, Dreyfuss G, Ohno S. 2006. Binding of a novel SMG1-Upf1-eRF1-eRF3 complex (SURF) to the exon junction complex triggers Upf1 phosphorylation and nonsense-mediated mRNA decay. Genes Dev 20: 355-367.

Khajavi M, Inoue K, Lupski JR. 2006. Nonsense-mediated mRNA decay modulates clinical outcome of genetic disease. Eur J Hum Genet 14: 1074-1081.

Kozak M. 1986. Point mutations define a sequence flanking the AUG initiator codon that modulates translation by eukaryotic ribosomes. Cell 44: 283-292.

Kozak M. 1987. Effects of intercistronic length on the efficiency of reinitiation by eucaryotic ribosomes. Mol Cell Biol 7: 3438-3445.

Kozak M. 2001. Constraints on reinitiation of translation in mammals. Nucleic Acids Res 29: 5226-5232.

Kozak M. 2002a. Emerging links between initiation of translation and human diseases. Mamm Genome 13: 401-410.

Kozak M. 2002b. Pushing the limits of the scanning mechanism for initiation of translation. Gene 299: 1-34.

Kuzmiak HA, Maquat LE. 2006. Applying nonsense-mediated mRNA decay research to the clinic: progress and challenges. Trends $\mathrm{Mol}$ Med 12: 306-316.

Le Hir H, Gatfield D, Izaurralde E, Moore MJ. 2001. The exon-exon junction complex provides a binding platform for factors involved in mRNA export and nonsense-mediated mRNA decay. EMBO J 20: 4987-4997.

Low SC, Berry MJ. 1996. Knowing when not to stop: selenocysteine incorporation in eukaryotes. Trends Biochem Sci 21: 203-208.

Maquat LE. 2004. Nonsense-mediated mRNA decay: splicing, translation and mRNP dynamics. Nat Rev Mol Cell Biol 5: 89-99.

Maquat LE, Gong C. 2009. Gene expression networks: competing mRNA decay pathways in mammalian cells. Biochem Soc Trans 37: 1287-1292.

Maquat LE, Li X. 2001. Mammalian heat shock p70 and histone H4 transcripts, which derive from naturally intronless genes, are immune to nonsense-mediated decay. RNA 7: 445-456.

Maser RS, Zinkel R, Petrini JH. 2001. An alternative mode of translation permits production of a variant NBS1 protein from the common Nijmegen breakage syndrome allele. Nat Genet 27: 417421.

McDonald DR, Mooster JL, Reddy M, Bawle E, Secord E, Geha RS. 2007. Heterozygous N-terminal deletion of IкB $\alpha$ results in functional nuclear factor $\kappa \mathrm{B}$ haploinsufficiency, ectodermal dysplasia, and immune deficiency. J Allergy Clin Immunol 120: 900-907.

Moriarty PM, Reddy CC, Maquat LE. 1998. Selenium deficiency reduces the abundance of mRNA for Se-dependent glutathione peroxidase 1 by a UGA-dependent mechanism likely to be nonsense codon-mediated decay of cytoplasmic mRNA. Mol Cell Biol 18: $2932-2939$.

Moumne L, Fellous M, Veitia RA. 2005. Deletions in the polyAlaninecontaining transcription factor FOXL2 lead to intranuclear aggregation. Hum Mol Genet 14: 3557-3564.

Nagai T, Ibata K, Park ES, Kubota M, Mikoshiba K, Miyawaki A. 2002. A variant of yellow fluorescent protein with fast and efficient maturation for cell-biological applications. Nat Biotechnol 20: 87-90.

Nagy E, Maquat LE. 1998. A rule for termination-codon position within intron-containing genes: when nonsense affects RNA abundance. Trends Biochem Sci 23: 198-199.

Neu-Yilik G, Kulozik AE. 2008. NMD: Multitasking between mRNA surveillance and modulation of gene expression. Adv Genet 62: 185-243.

Neu-Yilik G, Gehring NH, Thermann R, Frede U, Hentze MW, Kulozik AE. 2001. Splicing and $3^{\prime}$ end formation in the definition of nonsense-mediated decay-competent human $\beta$-globin mRNPs. EMBO J 20: 532-540.

Nicholson P, Yepiskoposyan H, Metze S, Zamudio Orozco R, Kleinschmidt N, Muhlemann O. 2010. Nonsense-mediated mRNA decay in human cells: mechanistic insights, functions beyond quality control and the double-life of NMD factors. Cell Mol Life Sci 67: 677-700.

Ozisik G, Mantovani G, Achermann JC, Persani L, Spada A, Weiss J, Beck-Peccoz P, Jameson JL. 2003. An alternate translation initiation site circumvents an amino-terminal DAX1 nonsense mutation leading to a mild form of X-linked adrenal hypoplasia congenita. J Clin Endocrinol Metab 88: 417-423.

Paulsen M, Lund C, Akram Z, Winther JR, Horn N, Moller LB. 2006. Evidence that translation reinitiation leads to a partially functional Menkes protein containing two copper-binding sites. Am J Hum Genet 79: 214-229.

Perrin-Vidoz L, Sinilnikova OM, Stoppa-Lyonnet D, Lenoir GM, Mazoyer S. 2002. The nonsense-mediated mRNA decay pathway triggers degradation of most BRCA1 mRNAs bearing premature termination codons. Hum Mol Genet 11: 2805-2814.

Pestova TV, Shatsky IN, Fletcher SP, Jackson RJ, Hellen CU. 1998. A prokaryotic-like mode of cytoplasmic eukaryotic ribosome binding to the initiation codon during internal translation initiation of hepatitis C and classical swine fever virus RNAs. Genes Dev 12: 67-83.

Poyry TA, Kaminski A, Jackson RJ. 2004. What determines whether mammalian ribosomes resume scanning after translation of a short upstream open reading frame? Genes Dev 18: 62-75.

Puel A, Reichenbach J, Bustamante J, Ku CL, Feinberg J, Doffinger R, Bonnet M, Filipe-Santos O, de Beaucoudrey L, Durandy A, et al. 2006. The NEMO mutation creating the most-upstream premature stop codon is hypomorphic because of a reinitiation of translation. Am J Hum Genet 78: 691-701.

Rebbapragada I, Lykke-Andersen J. 2009. Execution of nonsensemediated mRNA decay: what defines a substrate? Curr Opin Cell Biol 21: 394-402.

Rinne T, Clements SE, Lamme E, Duijf PH, Bolat E, Meijer R, Scheffer H, Rosser E, Tan TY, McGrath JA, et al. 2008. A novel translation re-initiation mechanism for the p63 gene revealed by aminoterminal truncating mutations in Rapp-Hodgkin/Hay-Wells-like syndromes. Hum Mol Genet 17: 1968-1977.

Romão L, Inácio A, Santos S, Avila M, Faustino P, Pacheco P, Lavinha J. 2000. Nonsense mutations in the human $\beta$-globin gene lead to unexpected levels of cytoplasmic mRNA accumulation. Blood 96: 2895-2901. 


\section{Neu-Yilik et al.}

Sanchez-Sanchez F, Ramirez-Castillejo C, Weekes DB, Beneyto M, Prieto F, Najera C, Mittnacht S. 2007. Attenuation of disease phenotype through alternative translation initiation in low-penetrance retinoblastoma. Hum Mutat 28: 159-167.

Santagata S, Gomez CA, Sobacchi C, Bozzi F, Abinun M, Pasic S, Cortes P, Vezzoni P, Villa A. 2000. N-terminal RAG1 frameshift mutations in Omenn's syndrome: Internal methionine usage leads to partial $\mathrm{V}(\mathrm{D}) \mathrm{J}$ recombination activity and reveals a fundamental role in vivo for the N-terminal domains. Proc Natl Acad Sci 97: 14572-14577.

Shyu AB, Wilkinson MF, van Hoof A. 2008. Messenger RNA regulation: to translate or to degrade. EMBO J 27: 471-481.

Silva AL, Romão L. 2009. The mammalian nonsense-mediated mRNA decay pathway: to decay or not to decay! Which players make the decision? FEBS Lett 583: 499-505.

Silva AL, Ribeiro P, Inácio A, Liebhaber SA, Romão L. 2008. Proximity of the poly(A)-binding protein to a premature termination codon inhibits mammalian nonsense-mediated mRNA decay. RNA 14: 563-576.

Singh G, Rebbapragada I, Lykke-Andersen J. 2008. A competition between stimulators and antagonists of Upf complex recruitment governs human nonsense-mediated mRNA decay. PLoS Biol 6: e111. doi: 10.1371/journal.pbio.0060111.

Stockklausner C, Breit S, Neu-Yilik G, Echner N, Hentze MW, Kulozik AE, Gehring NH. 2006. The uORF-containing thrombopoietin mRNA escapes nonsense-mediated decay (NMD). Nucleic Acids Res 34: 2355-2363.

Takeshita K, Forget BG, Scarpa A, Benz EJ Jr. 1984. Intranuclear defect in beta-globin mRNA accumulation due to a premature translation termination codon. Blood 64: 13-22.
Thein SL, Hesketh C, Taylor P, Temperley IJ, Hutchinson RM, Old JM, Wood WG, Clegg JB, Weatherall DJ. 1990. Molecular basis for dominantly inherited inclusion body $\beta$-thalassemia. Proc Natl Acad Sci 87: 3924-3928.

Thermann R, Neu-Yilik G, Deters A, Frede U, Wehr K, Hagemeier C, Hentze MW, Kulozik AE. 1998. Binary specification of nonsense codons by splicing and cytoplasmic translation. EMBO J 17: 34843494.

Trochet D, Mathieu Y, Pontual L, Savarirayan R, Munnich A, Brunet JF, Lyonnet S, Goridis C, Amiel J. 2009. In vitro studies of non poly alanine PHOX2B mutations argue against a loss-of-function mechanism for congenital central hypoventilation. Hum Mutat 30: E421-E431.

Waye JS, Eng B, Patterson M, Barr RD, Chui DH. 1997. De novo mutation of the $\beta$-globin gene initiation codon (ATG $\rightarrow$ AAG) in a Northern European boy. Am J Hematol 56: 179-182.

Welch EM, Barton ER, Zhuo J, Tomizawa Y, Friesen WJ, Trifillis P, Paushkin S, Patel M, Trotta CR, Hwang S, et al. 2007. PTC124 targets genetic disorders caused by nonsense mutations. Nature 447: 87-91.

Wells SE, Hillner PE, Vale RD, Sachs AB. 1998. Circularization of mRNA by eukaryotic translation initiation factors. Mol Cell 2: 135-140.

Yamashita T, Wu N, Kupfer G, Corless C, Joenje H, Grompe M, D'Andrea AD. 1996. Clinical variability of Fanconi anemia (type C) results from expression of an amino terminal truncated Fanconi anemia complementation group $\mathrm{C}$ polypeptide with partial activity. Blood 87: 4424-4432.

Zhang J, Maquat LE. 1997. Evidence that translation reinitiation abrogates nonsense-mediated mRNA decay in mammalian cells. EMBO J 16: 826-833. 

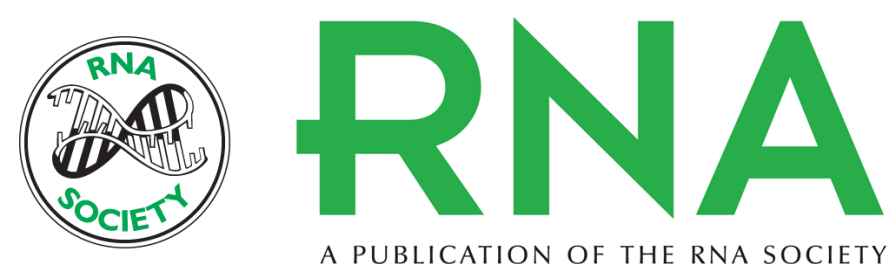

A PUBLICATION OF THE RNA SOCIETY

\section{Mechanism of escape from nonsense-mediated mRNA decay of human $\beta$-globin transcripts with nonsense mutations in the first exon}

Gabriele Neu-Yilik, Beate Amthor, Niels H. Gehring, et al.

RNA 2011 17: 843-854 originally published online March 9, 2011

Access the most recent version at doi:10.1261/rna.2401811

\section{Supplemental http://rnajournal.cshlp.org/content/suppl/2011/03/01/rna.2401811.DC1 \\ Material}

References This article cites 75 articles, 24 of which can be accessed free at: http://rnajournal.cshlp.org/content/17/5/843.full.html\#ref-list-1

Open Access Freely available online through the RNA Open Access option.

License Freely available online through the RNA Open Access option.
Email Alerting Receive free email alerts when new articles cite this article - sign up in the box at the Service top right corner of the article or click here.

